\title{
Formaçáo humana em tempos de pandemia: os docentes, sua vida e trabalho
}

\author{
Amone Inacia Alves ${ }^{1}$ \\ https://orcid.org/0000-0002-3131-6230 \\ Geralda da Cunha Teixeira Feraz ${ }^{2}$ \\ https://orcid.org/000-002-5161-5246 \\ Thaise Cristiane de Abreu Prudente ${ }^{3}$ \\ https://orcid.org/0000-0002-0874-5096
}

\section{Resumo}

Este artigo pretende discorrer sobre como pensar a formação humana, a partir do relato de educadores, em um momento em que as relaçóes humanas foram abaladas pela pandemia do Coronavírus, cuja letalidade e grau de contaminação atingiram de forma comunitária sobre a população mundial. Queremos analisar os impactos, em termos de educação, desses processos advindos da interatividade, da restrição das relaçóes sociais presenciais e da expansão de práticas não comuns na civilidade moderna, que são as atividades remotas. Para fins deste texto, convém inquirir: como pensar o mundo a partir de novas interaçóes? Como pensar a formação humana em meio ao trabalho remoto? Para tanto, utilizaremos para a escrita deste artigo uma análise a partir de categorias, como vida, trabalho e educação, apresentadas nas falas das autoras, que se propuseram a avaliar suas práticas nesse momento. Pretendemos com isso, contribuir para o debate sobre o tema, alargando as discussóes já feitas.

Palavras-chave: Formação humana, Pandemia, Atividades remotas.

\footnotetext{
${ }^{1}$ Licenciada em História pela Universidade Estadual do Sudoeste da Bahia - UESB , Doutora em Educação pela Faculdade de Educação, FE/UFG. É professora Associada na FE/UFG na Área de Fundamentos Filosóficos e Sócio-Históricos da Educação.

${ }^{2}$ Graduada pela PUC-GO, em Ciências Contábeis, graduada em Comunicaçáo Social - Radialismo pela UFG; especialista em Gestáo Escolar e Assessoria de Comunicação pela UFG e especialista Comunicação Pública pela ESPM, Mestranda em Educaçáo pela FE-UFG.

${ }^{3}$ Licenciada em Matemática e Física pela Fundaçāo Universidade do Tocantins. É especialista em Docência Universitária pela Universidade Estadual de Goiás e Mestra em Gestão do Patrimônio Cultural pela Pontifícia Universidade Católica de Goiás. É Doutora em Ciências da Educaçáo com ênfase em Ensino de Física pela Universidad Americana.
} 


\title{
Human training in times of pandemic: teachers, their life and work
}

\begin{abstract}
This article intends to discuss how to think about human formation, from the teachers' report, at a time like this in which human relations were shaken by the Coronavirus pandemic, whose lethality and degree of contamination reached community over the world population. We want to analyze the impacts, in terms of education, of these processes arising from interactivity, the non-presence of social relations and the expansion of something not common in modern civility, which are remote activities. For the purposes of this text, it is appropriate to inquire: how to think the world from new interactions? How to think of human formation in the midst of remote work? For this, we will use for the writing of this text an analysis from categories, such as life, work and education. We intend to contribute to the debate on the subject, extending the discussions already made.
\end{abstract}

Keywords: Human training, Pandemic, Remote activities.

\section{Introduçáo}

O mundo vai girando cada vez mais veloz A gente espera do mundo e o mundo espera de nós Um pouco mais de paciência Lenine

Este artigo advém da necessidade de contextualizar o trabalho docente em tempos de pandemia, ocorrida em razão da COVID-19. Embora a música de Lenine, Paciência, não tenha sido escrita com a finalidade de descrever o atual momento, o excerto selecionado como epígrafe deste artigo expressa um sentimento, que é a necessidade de viver em tempos tão sombrios e incertos na contramão da tristeza, dos impactos sobre nós dessa terrível doença. De repente, fomos obrigados a exercer nosso ofício de nossas casas, em meio a notícias tão tenebrosas de conhecidos (ou não) adoecidos, internados, em meio ao caos provocado pela ausência de leitos em hospitais, de equipamentos adequados ou profissionais da saúde em número razoável. Então, cabe-nos investigar: quais são as condiçóes de vida e trabalho do professor em momento de atividades remotas? Como se caracteriza a docência em um momento em que a vida privada do professor se vê exposta na atividade pública, no caso, a aula?

Para tanto, propusemo-nos a pensar a formaçáo desse docente, trabalhando essa ideia, a partir do que conceitua Libâneo (2004), ou seja, 
concebendo-a como a composição de elementos teóricos que são postos em movimento, por meio da experiência em situaçóes práticas vivenciadas. Partindo dessa concepção, percebemos que o mundo que se vislumbra, em que as atividades presenciais foram substituídas por remotas, sentimo-nos impelidos a rever conceitos iniciais da formação, como, por exemplo, ser docente em uma época como a que vivemos.

No momento em que a Organização Mundial da Saúde (OMS) pautou as decisôes governamentais de isolamento social, cresceram as demandas pelo ensino remoto, mediado por tecnologias educacionais, gerando uma confusão conceitual entre $\mathrm{EAD}$, modalidade de ensino com legislação própria, e ensino remoto ou aulas não presenciais, uma alternativa imposta ao contexto da realidade pandêmica.

Então, é objeto deste texto discutir a docência e as condiçôes de vida e trabalho dos professores no contexto da pandemia de COVID-19. Trabalharemos como o neoliberalismo aplicado em países, como o Brasil, teve seus pressupostos colocados em cheque em razão da pandemia. Recorremos a autores que descrevem a categoria trabalho à luz da tradição marxista, como Silva (1992) e Alves (2010). Na segunda parte, daremos voz às educadoras que atravessam o momento em meio a atividades docentes, sendo: uma professora universitária, uma professora da educação básica da Rede Estadual e outra da educação básica da Rede Privada de ensino.

\section{O neoliberalismo posto à prova na pandemia do covid-19}

O mundo desnudado a partir dos anos 1990, em meio ao crescente conservadorismo e ao desmonte do Estado do Bem-Estar Social, trouxe novos desafios para a vida social, mostrando a necessidade de uma sobreposição de demandas econômicas para a tessitura da sociedade. O avanço da COVID-19 mostrou aos países a precariedade dos serviços provocados pelo Estado mínimo, as dificuldades de impedir que o caos se instaurasse ainda mais, devastando sobremaneira os serviços, sobretudo de educação e saúde, tão sofríveis nos deveres políticos desses países.

No ano de 2020 nos deparamos com uma pandemia e percebemos que o Estado precisa investir em um sistema de saúde coeso, com investimentos 
maciços em saúde pública ${ }^{4}$, não apenas de saúde semi-intensiva, mas em saúde básica, com atendimento universal a todos, indiscriminadamente. Os países, como o Brasil, que possuem sistemas únicos de saúde, como o SUS, perceberam que longe de fazerem opção pelo sistema privado, precisavam publicizar ações exitosas por esse sistema público, gratuito e universal. Igualmente importantes, os sistemas educacionais também receberam destaque, por sua abrangência, de modo a atender os estudantes carentes, com materiais que subsidiem sua formação enquanto não podem ir às escolas, fechadas por tempo indeterminado.

Dardot e Laval (2016), em sua obra "a nova razão do mundo: ensaio sobre a sociedade neoliberal”, nos apresentaram a ideia de que o neoliberalismo, mais do que uma ordem econômica, pressupôs um ordenamento ideológico, cujo sistema normativo ampliou sua influência sobre as relaçóes sociais e todas as esferas da vida. Com base em ideais de individualismo, valores meritocráticos e competitivos, as pessoas ditaram seus princípios a partir dessa ótica, permeando relaçóes familiares, de trabalho e de sociedade.

Dito isso, os países que adotaram essas medidas neoliberais não apenas as recolocaram para o âmbito das economias, sobejamente tomadas por essa premissa, mas também passaram a adotar em suas vidas práticas, interiorizando ideias pautadas nessa nova racionalidade, em que o indivíduo se sobrepóe ao coletivo e as minorias são deixadas sistematicamente a reboque da exclusão.

Acrescentamos que Ricardo Antunes (2020), ao discutir as nefastas consequências do novo Coronavírus, assevera que se trata de uma letífera combinação entre a crise estrutural do capitalismo e a crise sociopolítica atual. A destruição sistemática da legislação social protetora do trabalho, acirrada na pandemia, traz, na visão do autor, com a qual comungamos, que há uma divisão social, de gênero e raça no trabalho, que contribui para a exclusão social, de modo que a pandemia causa maiores estragos à classe trabalhadora

\footnotetext{
${ }^{4}$ Segundo o Conselho Nacional de Saúde (2020), com a implementaçáo da Emenda Constitucional 95/2016, conhecida como PEC dos gastos, houve uma reduçáo considerável nos investimentos da saúde. Quando a emenda entrou em vigor em 2017, os investimentos em saúde eram de 15, 77\%, passando a ser $13,54 \%$. O colapso do sistema de saúde pelos baixos recursos reverberou na ausência de atendimento, significando um grande número de mortos.
} 
feminina do que à masculina, e mais à mulher negra e indígena do que à branca.

A escola, como instituição que possui uma verve de perpetuação da vida social, possui o papel de, além da reprodução ampliada do Capital, adequar o processo civilizatório, a fim de ampliar "[...] a moralidade das mais amplas massas populares às necessidades do contínuo desenvolvimento do aparelho econômico de produção e, portanto, de elaborar também fisicamente tipos novos de humanidade" (GRAMSCI, 2011, p. 23).

Nessa perspectiva, cabe aos trabalhadores investirem na educação para todos, a fim de se alterarem as relaçóes sociais, contribuindo, assim, para o processo revolucionário, coadunando com a assumência popular do Estado. Sem alterarem essas condiçôes objetivas, não seria possível o corolário da revolução. Nessa perspectiva, Marx contrapunha aos argumentos dos liberais clássicos, como Adam Smith, de que aos trabalhadores não cabiam a escolarização, pois assim superariam a divisão do trabalho, método utilizado pela classe dominante para expandir o capital da classe burguesa.

Aos poucos, essa instituição milenar, cooptada pela égide liberal ${ }^{5}$, também pautou-se na racionalidade neoliberal, implantando modelos de individualismo, meritocracia e competitividade. Luiz Carlos de Freitas (2012, p. 382) afirmou que o tecnicismo que se apresenta a partir dessa ótica está revestido de uma teoria da responsabilização, meritocrática e gerencialista, com ênfase nos "processos de gerenciamento da força de trabalho na escola (controle do processo, bônus e premiações). Desse modo, foram aperfeiçoados mecanismos de cooptação desses sujeitos e de controle excessivo sobre suas práticas, fazendo-os engrenagens úteis ao sistema.

Assim, o ambiente escolar absorveu essa concepção, impondo uma outra forma de organização, primadas pela empresa. Agora antagonistas, professores e estudantes encontram-se em uma batalha por maior desempenho e produtividade, impondo novos padróes de comportamento e um novo cotidiano.

Sardinha (2013, p. 20), ao mostrar a simbiose entre o Estado e o empresariado na educação brasileira, após a opção neoliberal, assevera que

\footnotetext{
5 Alguns liberais, como Adam Smith, defendiam a ideia de acesso à escola, como forma de garantir o rol de oportunidades para a população em geral. No entanto, vislumbra que as relaçóes econômicas de mercado são a única forma de distribuiçáo dos bens, a fim de manter o equilíbrio entre a demanda crescente e uma oferta limitada advindas da natureza da produçấo e distribuiçáo de bens (ROSA, 2015).
} 
[...] a suposta "novidade" está na forma particular como a reproduçáo ampliada do capital é operada pelos setores dominantes. Sob a égide dos princípios gerenciais, da difusão de um modo de vida competitivo e individualista, que aparecem como pilares de uma inovação técnica $\mathrm{e}$ dos métodos pedagógicos difundidos na escola pública, a classe dominante, com o expressivo predomínio da fraçáo financeira, veicula o projeto de reconstrução da hegemonia política no novo ciclo econômico. Fazem política sem o dizer - a classe hegemônica reproduz a coerção sob forma de liberdade (termo que lhes é muito caro) enquanto suas instituiçóes estão imbricadas nas políticas e práticas do Estado e influenciam diretamente nas relaçóes de poder entre governa.

Essa naturalização sobre o lugar competitivo que se tornou a escola tem nos despertado para a possibilidade de se pensar esse espaço como aquele responsável pela formação humana, pela socialização e por projetos que levem em conta a vida em sociedade.

Contudo, todos esses projetos foram açodados pelas contingências da COVID-19. De repente, como já foi dito, as escolas foram fechadas. Se havia uma perspectiva individual, esse individualismo acirrou as contradiçóes, sendo que as pessoas passaram a participar de atividades remotas, sem contato humano presencial. $\mathrm{O}$ cada um por si virou uma realidade, sendo impossível pensar na socialização escolar. Surgiu a necessidade de se repensar o espaço da escola, o lugar da aula e a atribuição de tarefas a serem desenvolvidas. Além disso, agudizaram as desigualdades escolares tributárias das desigualdades sociais com a grande quantidade de estudantes que não puderam estudar em razão da ausência de computadores, celulares ou até mesmo de acesso à internet, para o acompanhamento remoto das atividades escolares.

As reflexóes devem se pautar por uma outra racionalidade, que subverta a ordem meritrocrática e individualista. Biesta (2018, p. 21) aponta:

Nas sociedades contemporâneas existem muitas expectativas sobre o que as escolas devem fazer. Estas incluem a instrumentalização de crianças e jovens para o mundo do trabalho, a sua transformação em cidadãos democráticos ou a criação de uma sociedade coesa e inclusiva. O que une essas expectativas é que elas se aproximam da escola como uma espécie de instrumento para resolver problemas da sociedade. A escola é tratada como tendo uma função para a sociedade e, portanto, como uma instituição que deve ser funcional e útil para ela. $\mathrm{O}$ perigo 
dessa maneira de pensar é que outras questóes - como o que a escola deve cuidar ou proteger - desaparecem facilmente do campo de visão.

Repensar o papel da escola é urgente, principalmente no que diz respeito à sua funcionalidade de supressão dos problemas sociais. A escola deve ser o ambiente em que as crianças aprendam como viver em sociedade e quais premissas devem orientar esse convívio e em tempos de pandemia, o não-lugar é algo preocupante para pensarmos qual papel que assume na sociedade, em se tratando de um período pandêmico. No entanto, o distanciamento das rotinas tornou professores e estudantes aprendizes de um modo de viver completamente diferente, mediados por tecnologias educacionais. Então, cabe-nos indagar: como se caracteriza o trabalho do docente em meio a tudo isso?

\section{O trabalho, o mundo e a vida}

Paula Sibília (2008), ao discorrer sobre o impacto das tecnologias sobre as pessoas, reporta ao filósofo Gilles Deleuze, que denominou as sociedades atuais como aquelas que precisam exercer o controle. Para o autor, a expressão desses tempos em que as tecnologias assumem a centralidade do modo de viver, esse "monstro" criado torna-se uma organização sob a égide do capitalismo, caracterizado pela superprodução e consumo, que geram grandes aglomerados empresariais que controlam o fluxo econômico, como o fluxo da vida.

Para a autora, ao fazerem isso, as tecnologias criam uma nova subjetividade, com base no que ela chama de subjetividade autodirigida, em que os sujeitos se tornam ensimesmados, presos por uma corrente imaginária de laços superficiais que são as redes. Em uma outra obra (2012), Redes ou Paredes: A escola em tempos de dispersão, Sibília reflete sobre os dispositivos disciplinares que nortearam a escola e como esses novos dispositivos (tecnologias educacionais) são postos à prova em uma sociedade em que os muros da escola não conseguem mais exercer o controle disciplinar dessa instituição, nos moldes dos séculos que antecederam à sua criação.

Nesse âmbito, é relevante que essa "nova" instituição se adeque aos novos tempos, o que náo requer apenas disciplina para aprender, mas formas 
de despertar o capital humano ${ }^{6}$, capaz de mobilizar competências e habilidades para o preparo para o emprego, para o serviço empreendedor e para o trabalho em equipe. Nesse sentido, o docente assume cada vez mais o papel de prestador de serviços e o estudante, de cliente. Desse modo, subvertem as relaçôes e os papéis da escola, sobretudo, de seus principais atores: professores e alunos.

Biesta (2018, p.23), ao discorrer sobre os perigos do reducionismo do ensino, confundido com a educação, tarefas da escola na sociedade, afirma

Juntamente com a qualificação e com a socialização, sugere-se que a educação deva sempre ter um interesse no que, com um termo técnico, trata-se neste trabalho como subjetivação. Isso tem a ver com a possibilidade de que crianças e jovens náo adotem apenas uma identidade particular, não sejam apenas parte de comunidades e tradiçóes específicas, apenas objetos das intençóes e açóes de outras pessoas, mas existam como (um) sujeito por direito próprio, capaz de suas próprias açóes e disposto a assumir a responsabilidade pelas consequências dessas açôes. Educação, em outras palavras, nunca é apenas para qualificar crianças e jovens e oferecer-lhes um lugar particular na sociedade. A capacidade de assumir uma perspectiva crítica para com tradiçóes, práticas, modos de fazer e de ser existentes, também se dá após sua saída da escola.

Com isso, o autor questiona o alijamento da escola ao restringir o seu papel ao domínio da qualificação, em desprezo às demais questóes igualmente importantes na formação humana: conteúdo, tradição e liberdade do estudante como sujeito. Daí decorre a crítica à confusão entre aprendizagem e educação, sendo essa última um quadro mais amplo de possibilidades, que requer organizar os itinerários da socialização e subjetivação, formando sujeitos livres para pensarem sobre si mesmos no mundo.

Em tempos de pandemia, em que as escolas foram fechadas e as aulas remotas se tornaram prática recorrente nos países, o papel de formação humana que as instituiçóes exerce é colocado em prova. Há uma crítica ao conteudismo nas aulas náo presenciais, em que o preparo para os exames se

\footnotetext{
${ }^{6}$ Esboçado por Theodor Schultz (1973, p.31), refere-se à ideia de que o conhecimento, convertido em capital, refere-se à uma capacidade de aquisição individual, sendo de responsabilidade do indivíduo essa aquisição, imprescindível para o aumento da produtividade.
} 
sobrepóe ao preparo para a vida nesse momento de incertezas. Questiona-se a demanda pela autonomia intelectual que muitos alunos não possuem, mas que é imprescindível nesse contexto de atividades remotas. $\mathrm{O}$ trabalho do professor também é questionado, pois há uma necessidade eminente de se adequar às plataformas, às novas tecnologias, tendo que se desdobrar em um conjunto de atividades antes desconhecidas. Questóes como adoecimento, estresse e falta de preparo para as novas mudanças são olvidadas nessas narrativas sobre trabalho docente.

De acordo com o Conselho Nacional dos Secretários de Educação, o Consed, 25 estados brasileiros e o Distrito Federal estáo adotando a modalidade remota para os trabalhos realizados, seja em aulas transmitidas pela televisão, plataformas virtuais ou mesmo os dois formatos (Brasil de fato, 2020). Para a presidenta do Consed, Cecília Amendola, "não há um padrão específico nacional. Por conta da pandemia, o carro estava andando e a gente teve que começar a fazer. Cada estado começou a se virar sozinho, achar uma saída, recriar as atividades, e os professores também".

Convém ressaltar que apesar do esforço de oferta dessas aulas remotas, as contradiçóes sociais emergiram em um cenário em que os estudantes pobres foram excluídos dessas aulas, pois uma pesquisa do Centro Regional de Estudos para o Desenvolvimento da Sociedade da Informação (Cetic.br), que auxilia o Comitê Gestor da Internet no Brasil na Implementação de projetos e decisóes, apontou que 39\% dos domicílios brasileiros não têm acesso à internet por falta de computador (BRASIL DE FATO, 2020)

Então, com base nesses improvisos, a função docente também teve que ser ressignificada, trazendo novos contornos para o trabalho docente. Alves (2010, p. 95) ao analisar o trabalho docente, organiza essas ideias da seguinte forma:

[...] a primeira parte do princípio de que a docência é uma forma laboral, por isso passível de ser tratada como atividade humana de trabalho; a segunda, por sua vez, postula que, como forma laboral particular, a docência se encontra com a realidade mais ampla do mundo do trabalho, decorrendo daí o fato de que suas qualidades são objeto de apreciação social quanto ao seu valor.

Partindo desse raciocínio, ao considerar a docência como atividade humana, podemos afirmar que essa atividade está suscetível às diversas 
vicissitudes do mundo do trabalho, como a questão da formação inicial e continuada, ao âmbito da cultura, à relação com os saberes, à disposição institucional referente aos ordenamentos escolares, à legislação educacional, bem como ao que dispóe o ambiente externo de sua atividade, como impactos econômicos, sociais e políticos. No momento em que a pandemia se configura como realidade, essa atividade realizada também está subordinada aos novos desenhos, em uma perspectiva tanto de incertezas como de materialização de uma realidade diferente.

Ao dizer que esse trabalho na escola foi solapado pelo seu fechamento, convém entender os ajustamentos psíquicos e de ordem material que essa nova situação trouxe para a vida do professor, pois a sua casa virou a sala de aula e seus tempos de lazer foram tomados e absorvidos por esse novo modelo educacional: remoto ou híbrido (conjugando atividades semipresenciais com aquelas remotas).

Os relatos a seguir visam a mostrar o cotidiano docente no mundo pandêmico. Pretendemos, com isso, apresentar o olhar sobre a situação, a partir de três docentes: um do ensino superior e outros dois da educação básica nas redes estadual e municipal.

\section{Relato de uma professora de ensino superior}

No dia 15 de março, em pleno domingo, soubemos que a Faculdade de Educação, onde trabalho, seria fechada, com a implantação de atividades remotas. Naquele dia, a universidade soltou uma nota, onde dizia, ancorada pela orientação da Organização Mundial da Saúde (OMS), do Comitê da UFG para o gerenciamento das açóes da COVID-19 e da nota técnica da Secretaria Estadual da Saúde, as aulas seriam suspensas, bem como quaisquer atividades presenciais. Desse modo, nos vimos realizando nossas atividades em casa de modo ininterrupto. Daria aulas na segunda-feira, dia 16, tendo que me deslocar até a instituição para informar aos estudantes que não tinham sido previamente avisados sobre a decisão da universidade.

Naquele momento, tínhamos mais dúvidas do que certezas. Achava que ficaríamos no máximo um mês afastados de nossas atividades, sendo que mais tarde saberia que as minhas previsóes estavam completamente erradas.

Entáo, me vi em um universo completamente diferente, em que estavam vedados contatos humanos, reunióes com colegas, aulas com meus 
alunos e demais atividades que demandavam de um contato presencial. Filhos em casa, tarefas escolares, comida, lazer, limpeza, tudo isso ao mesmo tempo, acrescendo da vida acadêmica que não parava: pareceres de revistas, bancas, artigos, avaliação de projetos, lives e reunióes, reunióes e mais reunióes. Participei de uma reunião que a colega falava baixo para não acordar seu bebê que estava no peito. Uma prima me contava de uma aula que assistia que a professora precisou amamentar seu filho, que praticamente a desnudou para seus alunos. Nesse mundo da internet, nada eram flores. Via que as pessoas não conseguiam acesso, a imagem falhava, o microfone ficava ligado, impedindo todos de ouvirem bem. Perdia a interação da fala, imprescindível ao debate. Não estávamos preparados para o mundo que se vislumbrava: de conexão remota. Enquanto a reunião, aula ou banca acontecia, o cotidiano da casa era completamente alterado: tocava a campainha, os cachorros insistiam em latir, o vizinho estava de mudança (apesar das advertências sobre aglomeraçóes de qualquer ordem), a música do vizinho tocava no seu mais alto som. Além disso, passavam os carros: da terra, do gás e da pamonha. Em casa, os familiares também não se entendiam sobre o trabalho realizado em casa, sendo que era muito comum os filhos gritando, a televisão ligada, a moto passando com o motor ensurdecedor, as panelas apitavam, os bichos brigavam (aqui em uma árvore em frente à minha casa tinha um casal de Araras que queriam marcar presença).

Em meio a esse turbilhão de coisas, um pensamento me atormentava: como, ainda em meio a tantos imprevistos, exigir eficiência do professor em um momento como esse? Como não surtar em meio a uma pandemia?

\section{Relato de um professor de Educaçáo Básica na rede estadual de Goiás}

Servidora técnica no Ensino Superior (Técnica em Assuntos Educacionais pela Faculdade de Educação Física e Dança da Universidade Federal de Goiás) e professora do ensino médio regular e da Educação de Jovens e Adultos (EJA) na rede estadual de Educação do Estado de Goiás, luto sistematicamente por uma educação pública, de gestão pública, gratuita, de qualidade socialmente referendada, capaz de contribuir para a emancipação, transformação e justiça social a partir do respeito às diferenças e à democracia, valorizando a pluralidade humana, a inclusão social, a tolerância, o respeito mútuo, a ética, a paz, a sustentabilidade socioambiental. 
Na realidade da Universidade, vivi os sabores da organização coletiva e humana, com a suspensão do calendário acadêmico, as notícias de diversos projetos de pesquisa e extensão para o combate ao novo Coronavírus; e, mais tarde, o dissabor do atropelo, da exclusão, da despreocupação com os que ficam para trás, com a decisão da retomada do calendário, via remota, sob o mote de "a universidade não pode parar", ou "tem aluno que precisa formar para trabalhar”, sem compreender o papel da Universidade na formaçáo humana em seu célebre tripé: ensino, pesquisa e extensão, e, mais ainda, sem lançar mão da exponencialização da necessidade de se pensar na coletividade para não naturalizar a tragédia em tempos de alta da COVID-19. Todavia, é sobre a rede estadual que me debruço a questionar a formação humana em meio ao trabalho remoto, bem como as bases da educaçáo durante a pandemia.

A escola é um espaço público, no qual as relaçóes sociais são humanas, plurais e diversas. Nesse diapasão, o público, o sujeito educacional, se preparou para relaçóes humanas presenciais, ou seja, o/a estudante se matriculou em um curso presencial e os/as professores(as) se dispuseram ao trabalho nessa modalidade, quando eis que, frente ao combate à COVID-19, se instaurou como solução a verdadeira "marmota", paliativa, improvisada, sem quaisquer fundamentos pedagógicos. Não podendo chamar de $\mathrm{EAD}$, que tem seus dispositivos legais e educacionais próprios, forjou-se o termo "regime especial de aulas não presenciais” pelo CEE (Resolução CEE/CP no 02/2020, alterada pela Resolução CEE/CP no 5, de 1/04/2020) e pela SEDUC, de sorte que exclui os estudantes já digitalmente excluídos e também aqueles que não possuem ferramentas eletrônicas ou internet de qualidade; e ainda expóem professores(as) que receberam o aviso de que, caso náo pudessem trabalhar em home office, teriam de ir à escola para acessar por lá o mundo online.

Os decretos do governo estadual, no 9.633 e $\mathrm{n}^{\circ}$ 9.634, se deram em $13 / 03$, dispondo sobre a suspensão das aulas presenciais e sobre a avaliação e adoção de medidas preventivas à disseminação do Coronavírus nas escolas públicas. No entanto, determinou-se que teria "aula normal" nos dias 16 e 17/03 para explicar aos/às estudantes a gravidade da crise sanitária. Assim, sem uso de máscara, sem álcool gel ou qualquer medida de segurança, estudantes, professores(as) e técnicos/as foram expostos/as em plena validade dos decretos. Acrescenta-se que já no início de abril, o dislate se intensifica e a SEDUC determina que diretor, secretário, auxiliar de secretaria, coordenador 
administrativo financeiro, executores de serviços auxiliares e vigias retornem às suas atividades e cumpram suas horas diárias.

Repentinamente professores(as) e, mormente, coordenadores(as) e diretores(as), são lançados(as) a uma carga exaustiva de trabalho. Além disso, subitamente estudantes evadem, mas o estado tergiversa uma preocupação e lança o decreto $\mathrm{n}^{\mathrm{o}} 9.643$, de 25/03, sobre o direito à alimentação durante o período de suspensão das aulas aos/às cadastrados(as) e beneficiados(as) pelo programa Bolsa Família.

A quantidade de formulários a serem preenchidos evidenciava a crueldade para com o/a trabalhador(a). Eu, particularmente, tive meu momento de desesperança quando percebi que apenas preenchia documentos enquanto via desaparecer os/as estudantes. Cheguei a enviar tudo o que era obrigada, desligar o celular e passar alguns dias inteiros em lágrimas de desespero, até porque a saúde mental jamais fora considerada pelos governantes e não seria em tempos pandêmicos.

Se antes da pandemia era difícil que as escolas estaduais em Goiás adotassem uma perspectiva emancipatória, potencializando o trabalho colaborativo e se mostrando enquanto um espaço articulado, participativo e autônomo, agora, em tempos pandêmicos, esses vieses não passam de uma longínqua utopia; coordenadores assistem às aulas, tutores não apenas acompanham, mas dão ordens em reunióes de planejamentos, potencializam as hierarquizaçóes das decisóes, planejamentos de aula são elaborados com replicação de trabalho em várias plataformas diferentes (em formulário do Excel, no SIAP, no Google Forms, em roteiro do Word etc.), de modo que se distancia cada vez mais o estudante como sujeito concreto, real, histórico, participativo no processo educativo e agente crítico-reflexivo.

Eu, que nem sabia da existência do Google Forms, tive de aprender a utilizá-lo para aplicar provas. Eu, que nunca gostei de fotos ou vídeos, tive de vencer medos, inseguranças, timidez, e lecionar geometria com programas novos, mas também pelo quadro-negro da minha casa por meio do Google Meet, alcançando um máximo de cerca de $10 \%$ de estudantes durante as aulas síncronas. Eu, que nunca poderia me imaginar em um processo semelhante, gravei vídeos curtos de no máximo dois minutos e me lancei a essa panaceia para evitar ainda maiores descompassos. Eu deixei de ser eu!

Para as aulas de Física na EJA, além do envio de atividades durante o período da aula pelo WhatsApp, cumprindo o horário da aula rigorosamente, 
incluindo lista de "presença", mas recebendo mensagem até às $2 \mathrm{~h}$, $3 \mathrm{~h}$ e $4 \mathrm{~h} 30 \mathrm{~min}$ da manhã, fui aprendendo aos novos moldes, como, por exemplo, enviei vários vídeos e filmes do YouTube, e só depois descobri que não podiam ser acessados porque o pacote de internet dos/as estudantes não permitia ver vídeos, então esse não seria um caminho adequado.

Adequei o conteúdo, a forma, organizei, sistematizei e ressignifiquei as atividades desenvolvidas, mas não tinha competência para garantir a inclusão e a equidade socioeducacional. Vi mulheres estudantes dizendo que só acessavam telefone quando o marido estava em casa ou que o namorado havia quebrado o celular, ou, ainda, que estava mal por estar apanhando do cônjuge, não permitindo acompanhar de modo síncrono; mães que dividiam o telefone com os/as filhos(as), priorizando-os para realizar as atividades escolares; pessoas negras relatando que em certos dias não havia sobrado dinheiro para adquirir pacotes de dados para acessar à internet; que estavam trabalhando dobrado e não tinham mais tempo; enfim, os relatos de reverberação de uma sociedade capitalista classista, machista, sexista, racista, excludente eram variados e repletos de dor.

Ao final do semestre na EJA, cerca de 58\% dos/as estudantes evadiu, e ainda assim o diretor afirmou que, frente ao cenário que averiguava, a nossa escola era, para ele, a melhor da cidade e do estado em termos de envolvimento dos/das profissionais e de lograr a participação dos/as estudantes, a partir do árduo trabalho dos/as docentes, do diretor em dialogar constantemente com todos/as e das coordenadoras, que ligavam para todos/as estudantes, buscando alcançar os/as que não tinham telefone e indo presencialmente à escola para enviar atividades aos/às que não tinham acesso à internet.

Eis que com exclusóes, dores, sem estrutura didático-pedagógica e física, sem uma real readequação dos conteúdos, sem planejamento, sem cumprir o art. $206 \mathrm{da} \mathrm{CF} / 88$, sobre a garantia de igualdade de condiçóes para o acesso e permanência na escola, chegamos ao pior dos cenários: o medo real da possibilidade de morte em eminência. Em meados de julho, a ameaça da volta às aulas presenciais com mais de 40 mil infectados e mais de 1000 mortes, com curva ascendente, fez surgir a mais tensa das férias escolares. Férias sem possibilidade de lazer em clubes, bares, festas, pela óbvia necessidade de não aglomeração, mas também férias com medo do apressamento da morte. 
Estados como São Paulo, que tiveram recuo da doença, estão voltando atrás quanto à reabertura das escolas, mas em Goiás tememos um verdadeiro genocídio. Fátima Gavioli, secretária de educação do estado de Goiás, insiste vorazmente no retorno presencial, ou híbrido e escalonado, como vocifera incessantemente. A secretária disse, em uma live em 15/07, que teve COVID, mas trabalhou muito e teve pensamentos positivos e por isso não teve nada. Disse:

Eu tive Covid-19. Eu fui fazer uma brincadeira, ganhei um teste de laboratório e foi positivo. E aí falavam: 'A senhora está com Covid'. Eu disse: 'Quer ver que eu não vou ter nada?'. Trabalhei durante todo o isolamento, trabalhei assustadoramente, náo tive tempo para ter nada porque a cabeça da gente comanda o nosso corpo. E se a nossa cabeça falar que não vamos ter nada, nós não vamos ter nada. Agora, se a cabeça falar: 'Não sei, estou com isso, com aquilo'. Aí tem que procurar especialista, tomar remedinho para poder ficar bem (LEITOJO, 2020, p. 01).

Ou seja, se escancara a ideia de que a culpa dos mortos é deles mesmos por falta de pensamentos positivos e de trabalho. No dia seguinte, a secretária foi ao Jornal Anhanguera dizer que foi mal interpretada e que "Todo o comportamento da secretária de Goiás foi pioneiro no que se refere a preservar e confiar na ciência”. Ao mesmo tempo Gavioli teima em não seguir a máxima da ciência, de isolamento social.

A Associação de Mobilização dos Professores de Goiás (AMPG), que representa professores da rede estadual, e da qual participo, prontamente escreveu uma nota contra o retorno das aulas presenciais, criou lives, participou de reunióes online, debateu nas redes sociais, elaborou uma pesquisa via Google Forms com docentes de todo o estado, produziu vídeos, fez uma petição online para retorno às aulas presenciais somente com vacina $\mathrm{e}$ segurança, sempre se posicionando bravamente pela vida e contra o retorno às aulas presenciais em pleno crescimento da curva de contágio no estado de Goiás.

Pelo Forms, a AMPG fez uma pesquisa entre os dias 18/07 e 21/07/2020, em que responderam ao questionário 4262 professores(as) e funcionários(as) de diferentes redes de ensino de todo estado de Goiás. Do formulário, constatamos que a maior parte dos entrevistados é composta por 
mulheres pardas, com pós-graduação lato sensu, de cidades do interior com menos de 100 mil habitantes, sendo que cerca de $94 \%$ tem entre 25 e 59 anos de idade. Da pesquisa, notamos que mais de $40 \%$ dos(as) entrevistados(as) usa transporte público para ir à escola esporadicamente ou sempre. Mais de $94 \%$ acha que 2020 não é o momento de voltar às aulas presenciais. Além disso, $83,3 \%$ acredita que as medidas de segurança relacionadas às escolas em que trabalham são fracas ou moderadas. Acrescenta-se que $91 \%$ pensa que o risco de contágio no exercício de trabalho nas escolas é alto ou muito alto. E ainda, mais de $90 \%$ acha que as escolas não estarão seguras para professores e alunos, até porque $86,1 \%$ acredita que as escolas não têm infraestrutura para garantir a segurança dos alunos e professores. Ou seja, é evidente o medo do retorno às aulas presenciais sem segurança, que só pode vir com a vacina.

O Fórum de Licenciaturas da UFG publicou uma nota de repúdio à adoção do regime especial de aulas não presenciais na educação básica em Goiás, no contexto da covid-19, seguida de uma solicitação coletiva para reprovação do Projeto de Lei que institui o Programa Goiás TEC no Ensino Médio de Goiás, e, por fim, uma nota repudiando a volta presencial das aulas. Além disso, professoras e professores dessa universidade produziram vídeos, que viralizaram com mais de 200 mil visualizaçóes. E assim seguimos em luta, agora pela sobrevivência!

$\mathrm{O}$ ensino remoto acabou por servir de adubo para o calamitoso e excludente projeto EJA-TEC do governo de Goiás, com início no segundo semestre do ano corrente, vendendo-se como um fruto inovador que culminará em rupturas epistemológicas tradicionais, quando é sabido que o uso de TICs não significa necessariamente romper com a educação tradicional, nem tampouco dá conta de resolver os reais problemas de falta de valorização profissional, de estrutura física adequada, de materiais didáticos, de investimentos diversos, de gestão democrática e autônoma. Ao contrário, o uso do mundo online neste momento serviu de ferramenta de exclusão socioeducacional. 


\title{
Relato de um professor de ensino fundamental Educaçáo Básica na rede municipal de Goiás
}

\section{A pandemia nos provoca: superá-la para continuar vivendo, superá-la para continuar educando!}

Parte 1: A realidade vista do meu quintal

\begin{abstract}
"A questão crucial imediata para esta era de trevas é a luta pela preservação da vida. Isso significa encontrar no presente as condiçôes para estancar a crise pandêmica com o apoio vital da ciência, e ao mesmo tempo, começar a desenhar outro sistema de metabolismo verdadeiramente humano - social. Estamos em um momento excepcional da história, daqueles raros momentos em que tudo que parece sólido, pode fenecer! Urge, então, inventar um modo de vida no qual a humanidade seja dotada de sentido em suas atividades mais vitais e essenciais." (ANTUNES, R. 2020, p. 22)
\end{abstract}

A pandemia nos apresentou um mundo de incertezas! A Educação definitivamente foi uma das áreas mais afetadas. As mudanças significaram uma guinada de 360 graus para a grande maioria das Escolas do Brasil e do mundo!

Por aqui, completamos três meses de um trabalho escolar permeado de desafios e novos planejamentos, para o que se convencionou chamar de "novo normal”. As tecnologias que antes eram parte dos nossos recursos didáticos passaram a ser a principal ferramenta de ensino e aprendizagem!

Os vínculos criados entre crianças/alunos e professores foram ressignificados; assim como os vínculos entre escola e crianças/alunos e pais precisaram ser fortalecidos. Uma nova relação baseada no que é necessário e possível tomou frente; a tolerância, o respeito e a compreensão são hoje princípios, mais do que nunca, basilares nesta relação intensa entre Escola e Pais. Os dias atuais têm nos possibilitado repensar o nosso papel. Não somos mais os mesmos!

O que na verdade poderia parecer o fim da escola como o lugar onde se dá a construçáo do saber, ainda que o ensino remoto nos tenha impelido a ir a lugares antes protelados, o distanciamento social evidenciou o quanto a Escola é imprescindível! Pensemos nisto. Pensemos no valor dos profissionais 
que diante das incertezas se lançaram se ressignificaram e estão fazendo a diferença na vida dos pequenos, dos adolescentes e jovens!

$\mathrm{Na}$ linha de frente, contra a pandemia da Covid-19 e em defesa da vida, os profissionais da educação têm sido responsáveis por milhares de estudantes, motivando-os, amenizando as ansiedades e angústias, fazendo-os comprometidos, promovendo a autonomia, norteando-os no uso adequado das TICs! Muito tem sido feito! Mais que conteúdos, nossas crianças e alunos têm tido a oportunidade de criar uma rotina, que os ajudam a manter a saúde mental e a acreditar que esta fase vai passar e que eles vão poder voltar para a Escola, rever seus amigos, acolher e serem acolhidos, abraçar seus professores, enfim, a continuarem a sua jornada formativa!

Por outro lado, a pandemia tem nos ensinado que ficar em casa pode ser uma boa oportunidade de conviver com nossos filhos com amorosidade, exercendo o nosso papel de pai e mãe que normalmente, em função da corrida contra o tempo, na busca de proporcionar "qualidade de vida" a eles, terceirizamos ou nos omitimos!

Longe da filosofia clichê que enxerga as crises como oportunidades, a reflexão que trago é essa: pela primeira vez ficamos cara a cara com um problema de proporçóes mundiais, sem um "plano b". A única alternativa que nos resta é enfrenta-lo! Ainda que não percamos de vista o papel do Estado como responsável e detentor de todas as ferramentas para possibilitar que o ensino remoto aconteça, para todos, sem exceção. Cabe a nós educadoras e educadores, enfrentar o caos, não nos paralisarmos, cobrar recursos e possibilidades que nos permita contribuir para que as desigualdades não façam com que nossas crianças e jovens sejam revitimizados, já que na realidade escancarada, os mais empobrecidos são e serão os mais atingidos!

Parte 2: Mês de agosto: Gestão de pequenas escolas

"E quanto ao pequeno "empreendedor" (que descrevi em O Privilégio da servidão como sendo, simultaneamente, burguês-de-si-mesmo e proletário-de-si-próprio), que em meio à pandemia não tem o que vender (pois náo há consumidores), nem renda, nem previdência, nem convênio de saúde? Como será possível driblar o trabalho dito flexível, digital, "moderno", que tenderá a se intensificar enormemente se o capital pandêmico continuar a comandar o mundo segundo seus interesses?" (ANTUNES, R. 2020, p. 14) 
O distrato contratual na Educação Infantil atingiu em Goiânia, no mês de maio, cinquenta por cento. Para os gestores das escolas que trabalham com esta modalidade de ensino, a maioria de pequeno porte, o número de evasão das crianças das salas de aulas significa fechamento de turmas e das próprias escolas. A realidade das escolas privadas, microempresas, lidando com as adversidades, está latente. Hoje o maior desafio é evitar a evasão, a inadimplência e, consequentemente, demissóes no quadro de funcionários e no corpo docente. O fato é que, mesmo na categoria Educação, as escolas privadas de pequeno porte estão no limbo. Sem recursos para enfrentar a pandemia com o mínimo de tranquilidade e garantindo os empregos dos servidores, por vezes são vistas e julgadas com o mesmo peso dado às grandes empresas educacionais.

A pandemia nos faz lembrar da fábula do rato, que tem a seguinte moral: "Na próxima vez que você ouvir dizer que alguém está diante de um problema e acreditar que o problema não the diz respeito, lembre-se de que, quando há uma ratoeira na casa, toda fazenda corre risco. O problema de um é problema de todos ”. Deparamo-nos com a ausência de políticas públicas sérias que dão conta dos desafios para milhares de alunos da rede pública, e que ainda não preveem linhas de crédito para as pequenas empresas educacionais da rede privada, entre elas as escolas de Educação Infantil, que empregam parcela significativa de profissionais; assim como a postura do Poder Público, que não dá conta da demanda da Educação Infantil, o que faz com que enxerguemos um futuro desastroso, de mais desigualdades e mais precariedade na Educação brasileira.

\section{Consideraçóes finais}

Neste texto abordamos o papel formativo da escola, no que tange ao seu projeto de sociedade, diante da pandemia do Sars-Covid/2019. Mostramos as dificuldades provocadas e como a comunidade escolar teve que se adaptar aos novos tempos e aos problemas evocados pela pandemia. Notamos que não está sendo fácil enfrentar as questóes postas, pois a precariedade das escolas públicas reverberou no desempenho dos seus estudantes, no que tange às dificuldades de acesso, pela ausência de planos de dados para assistir às aulas. 
Para os docentes e servidores, além da exaustiva jornada, da ausência de espaços destinados à aula e das dificuldades de acesso, transmissão ou organização dos tempos e espaços, os docentes se encontram em um momento difícil de suas carreiras, sendo expostos na intimidade para suas turmas de estudantes. A casa virou a sala e os tempos e movimentos se misturaram nessa simbiose entre o espaço da vida e o espaço do trabalho.

A partir deste trabalho buscamos compreender como (re)inventar essa instituição milenar, sobretudo, quanto aos papeis assumidos pelos professores e estudantes diante dessa nova organização dos tempos e espaços, em razão desses eventos. São tempos difíceis, de muitos problemas de adaptação, que trouxeram inúmeras perdas para todos os que participam desse processo.

\section{Referências}

ALVES, Wanderson Ferreira. O trabalho dos professores: saberes, valores, atividade. Campinas: Papirus, 2010.

ANTUNES, R. Coronavirus: O trabalho de sob o fogo cruzado. São Paulo: Boitempo, 2020.

BIESTA, G. O dever de resistir: sobre escolas, professores e sociedade. Educação. Porto Alegre, v. 41, n. 1, p. 21-29, jan.-abr. 2018.

CONSELHO NACIONAL DA SAÚDE. Saúde perdeu 20 bilhöes em 2019 por causa da EC 95/2016. Disponível em: http://www.conselho.saude.gov.br/ultimas-noticias-cns/1044-saude-perdeur-20-bilhoes-em-2019-por-causa-da-ec-95-2016\#:- :text=Em\%202017. Acesso em: 4 jun. 2020.

FREITAS, L. C. Os reformadores empresariais da educação: Da desmoralização do Magistério a destruição do Sistema Público de Educação. Revista Educação e Sociedade. Campinas, v. 33, n. 119, p. 379-404, abr., jun.2012.

GRAMSCI, A. Maquiavel: notas sobre o Estado e a política. Rio de Janeiro: Civilização Brasileira, 2011. 
HOBSBAWM, E. Adeus a tudo aquilo. In BLACKBURN (org). Depois da queda - o fracasso do comunismo e o futuro do socialismo Rio de janeiro: Paz e Terra, 1992.

LEIJOTO, M. Fátima Gavioli diz que não sentiu impacto da Covid-19 porque 'trabalhou muito'. O Popular, Goiânia, 16 de julho de 2020, Seção Cidades.

LIBÂNEO, J. C. Organização e gestão da escola: teoria e prática. 5. ed. revista e ampliada. Goiânia: Editora Alternativa, 2004.

MARX, K. O Capital. Volume I e II. Apresentação de Jacob Gorender; coordenação e revisão de Paul Singer; Tradução de Regis Barbosa e Flávio R. Kothe. Editora Nova Cultural Ltda., 1996

ROSA, D. B. A. As ideias defendidas por Adam Smith para a educação: suas influencias nas orientaçóes curriculares da Educação Básica do Estado de Mato Grosso. IN Educere: XII Encontro Nacional de Educação. Curitiba, 2015.

SAMPAIO, Cristiane. Professores, pais e alunos apontam dificuldades e limitações do ensino à distância. Revista Brasil de fato. 04 mai. 2020. Disponível em: https://www.brasildefato.com.br/2020/05/04/professorespais-e-alunos-apontam-dificuldades-e-limitacoes-no-ensino-a-distancia. Acesso em: 2 jun. 2020.

SARDINHA, Rafaela Campos. O Projeto Procentro e as Escolas Charter: investigação de um modelo educacional defendido pela Fundação Itaú Social. 2013. Dissertação (mestrado em ciências biológicas) - Programa de PósGraduação em Ciências Biológicas. UFRJ, Rio de Janeiro, 2013.

SIBILIA, P. O show do eu. São Paulo: Autêntica, 2015. Disponível em: https://comunicacaoeesporte.files.wordpress.com/2018/02/aula-show-do-eude-paula-sibilia-1.pdf. Acesso em: 04 mai. 2020.

SIBILIA, P. Redes ou paredes? A escola em tempos de dispersão. Tradução Vera Ribeiro. Rio de Janeiro: Contraponto, 2012.

SCHULTZ, T. W. O Capital Humano: investimentos em educação e pesquisa. Tradução de Marco Aurélio de Moura Matos. Rio de Janeiro: Zahar, 1973. 
Polyphonía, v. 31/1, jan.-jun. 2020

Recebido em: 09 ago. 2020

Aceito em: 28 ago. 2020 